\title{
Isolation of Chlamydia trachomatis from different areas of conjunctiva in relation to intensity of hyperendemic trachoma in school children in Southern Tunisia
}

\author{
S. DAROUGAR, B. R. JONES, T. DAGHFOUS, ${ }^{1}$ AND R. HEJAZI \\ From the Virus Laboratory, WHO Collaborating Centre for Reference and Research on Trachoma and \\ other Chlamydial Infections, Department of Clinical Ophthalmology, Institute of Ophthalmology, London, and \\ 'l'Institut d'Ophtalmologie de Tunis, Tunisia
}

SUMMARY The simplified one-passage technique of culture in irradiated McCoy cells, in conjunction with certain other developments in technique, was used to isolate Chlamydia trachomatis from specimens collected from 78 children with trachoma in Douz, Southern Tunisia. The results show that C. trachomatis is not confined to the upper tarsal area of the conjunctiva in hyperendemic trachoma. The higher isolation rate and corresponding increase in the number of inclusions obtained from swabbings of the upper fornix and lower lid in addition to the conventional collection from the upper tarsus show the superiority of collecting specimens for culture from the whole conjunctiva. Specimens could be collected from the whole conjunctiva by using 1 swab for each eye and pooled for subsequent inoculation, so that the laboratory incurred no additional work. A close correlation was observed between isolation rate, together with the number of inclusions obtained in cell culture, and intensity of inflammatory disease in hyperendemic trachoma. The sensitivity and practicability of this cultural test should provide a valuable laboratory index for use in epidemiological and therapeutic studies of trachoma.

The simplified one-passage technique of culture in irradiated McCoy cells provides a rapid and sensitive test for the primary isolation of Chlamydia trachomatis (Darougar et al., 1971). Conjunctival swabbings (Darougar and Jones, 1971) and transport of clinical specimens frozen in a cryoprotectant medium in a liquid nitrogen refrigerator $\left(-180^{\circ} \mathrm{C}\right)$ (Darougar et al., 1972) have further increased the sensitivity and practicability of the test. With this cultural technique chlamydial isolates were obtained in up to $90 \%$ of cases of chlamydial ocular infections in London (Darougar et al., 1977), $68 \%$ of cases of non-specific urethritis (Alani et al., 1977), and from the cervix of $90 \%$ of patients suffering from chlamydial ocular infections and mothers of babies with TRIC ophthalmia neonatorum (Darougar et al., 1972).

The purpose of this study was to compare the isolation rate of $C$. trachomatis from specimens

Address for reprints: Dr S. Darougar, Institute of Ophthalmology, Judd Street, London, WC1H 9QS collected from the whole conjunctiva with the isolation rate from specimens collected from the upper tarsus alone (the conventional method), and to assess the relationship of the isolation rate to the severity of active hyperendemic trachoma.

\section{Subjects and methods}

Patients included in this study were selected from a group of children attending a primary school in Douz, Southern Tunisia, who were part of a longterm study of the natural history and the control of trachoma (Dawson et al., 1974; Dawson et al., 1976).

\section{CLINICAL EXAMINATION}

The clinical signs observed with a Haag-Streit slit-lamp in the cornea and conjunctiva were recorded on a proforma by means of an extension of the scoring system proposed for the study of trachoma (Dawson et al., 1975). The signs were graded from 0 to 3 , and the intensity of inflamma- 
tory disease of the upper tarsal conjunctiva and the whole conjunctiva was calculated by the method described elsewhere (Dawson et al., 1975).

\section{COLLECTION OF SPECIMENS}

The conjunctiva of each eye was anaesthetised with 2 to 3 drops of Jocaine (cocaine $\mathrm{HCl} 4 \mathrm{~g}$, adrenaline acid tartrate $0.15 \mathrm{~g}$, sodium metabisulphite $0.1 \mathrm{~g}$, neomycin sulphate $0.5 \mathrm{~g}$, chlorhexidine acetate $0.1 \%$ $5 \mathrm{ml}$, distilled water to $100 \mathrm{ml}$ ) (Darougar and Jones, 1971). Duplicate smears were taken from the upper tarsus of each eye for the detection of chlamydial inclusions by means of an indirect fluorescent antibody stain and Giemsa's stain. (The results of this study will be reported elsewhere.) After this conjunctival swabbings for the isolation of Chlamydia were collected from the upper tarsus of each eye. Separate swabbings were also collected from the upper fornix and lower lid conjunctiva of each eye. Paired swabs from the upper tarsus of the right and left eye were pooled in plastic capsules containing 2SP transport medium (Gordon et al., 1969). Similarly, swabbings from the rest of the conjunctiva (upper fornix and lower lid) of both eyes were pooled. All conjunctival swabbings were stored immediately in a portable liquid nitrogen refrigerator $\left(-180^{\circ} \mathrm{C}\right)$ for transport to the laboratory in London. Here they were stored in a refrigerator at $-70^{\circ} \mathrm{C}$ for a period of 6 to 9 months until they were inoculated into cell cultures.

\section{CELL CULTURE}

The methods of culture in irradiated McCoy cells and the identification of inclusions are described elsewhere (Darougar et al., 1971). The number of inclusions present in each coverslip at first passage was recorded.

\section{Results}

Seventy-eight children aged between 6 and 10 years with active trachoma were included in this study.

ISOLATION FROM DIFFERENT AREAS OF THE CONJUNCTIVA

Of 78 paired conjunctival specimens $C$. trachomatis was isolated from $23(29 \%)$ from the upper tarsus and $29(37 \%)$ from the rest of the conjunctiva (upper fornix and lower lids).

In culture the average ratio of the number of inclusions obtained from the upper tarsus to the number obtained from the whole conjunctiva was 1 to 14. Six cases were positive only in the upper fornix and lower lid, and in 4 of those the number of inclusions found was fewer than 7.
ISOLATION IN RELATION TO INTENSITY OF UPPER TARSAL CONJUNCTIVAL INFLAMMATION The isolation rates and the numbers of inclusions obtained from the whole conjunctiva for various grades of intensity of inilammation are shown in Table 1. The highest isolation rate $(82 \%)$ was obtained from cases of severe trachoma. The isolation rates from the upper tarsus in relation to McCallan's stages of trachoma are shown in Table 2.

\section{Discussion}

The simplicity, speed, and relatively non-traumatic nature of conjunctival swabbings used for this study confirms the previous report (Darougar and Jones, 1971) that swabbing is the method of choice for the collection of conjunctival specimens in field studies or for routine diagnostic laboratory work.

The results confirm the previous study (Darougar et al., 1971) that $C$. trachomatis is not confined to the upper tarsal area of the conjunctiva in hyperendemic trachoma. Collecting specimens from the upper fornix and lower lid, in addition to the conventional collection from the upper tarsus, increases the isolation rate.

It may be argued that initial scrapings of the conjunctiva may reduce the isolation rate of chlamydia from subsequent swabbings. However, studies by Darougar et al. (1971) have shown that, despite there being less chlamydial agent in subsequent specimens and regardless of the order of collection by swabbing or scraping, the second specimens were as frequently positive as the first

Table 1 Isolation of Chlamydia trachomatis in relation to the intensity of trachomatous inflammation in the whole conjunctiva

\begin{tabular}{llcl}
\hline $\begin{array}{l}\text { Grade of } \\
\text { severity }\end{array}$ & $\begin{array}{l}\text { No. of } \\
\text { patients }\end{array}$ & $\begin{array}{l}\text { No. of } \\
\text { positives }\end{array}$ & $\begin{array}{l}\text { Average no. } \\
\text { of inclusions }\end{array}$ \\
\hline 4-Severe & 11 & $9(82 \%)$ & 774 \\
3-Moderate & 37 & $18(49 \%)$ & 115 \\
2-Mild & 27 & $2(7 \%)$ & 16 \\
1-Trivial & 3 & 0 & 0 \\
\hline
\end{tabular}

Table 2 Isolation of Chlamydia trachomatis in relation to McCallan's stages of trachoma in the upper tarsus

\begin{tabular}{lccl}
\hline St .zges & $\begin{array}{l}\text { No. of } \\
\text { patients }\end{array}$ & $\begin{array}{l}\text { No. of } \\
\text { positives }\end{array}$ & $\begin{array}{l}\text { Average no. } \\
\text { of inclusions }\end{array}$ \\
\hline I & 9 & $2(22 \%)$ & 317 \\
II & 16 & $8(50 \%)$ & 754 \\
III & 53 & $19(36 \%)$ & 143 \\
\hline
\end{tabular}


specimens. The higher isolation rate and corresponding increase in the number of inclusions obtained from the whole conjunctiva show the superiority of collecting specimens from the whole conjunctiva over the conventional collection from the upper tarsus area alone. In this study specimens were collected from various areas with separate swabs. In routine work specimens could be collected from the whole conjunctiva with the use of 1 swab for each eye. These swabs should be pooled in 1 capsule for subsequent inoculation, thereby incurring no additional workload in the laboratory.

The high isolation rate of $82 \%$ obtained in cases of severe trachoma and the close correlation between the grades of intensity of trachomatous inflammation and the isolation rate in irradiated McCoy cells demonstrate the sensitivity of this cultural test in field studies and show that the test could be used as a laboratory index of severity of hyperendemic trachoma.

The distribution of isolation from the upper tarsus in relation to McCallan's stages of trachoma indicates that this classification is not a good index of the presence of $C$. trachomatis and does not correlate with the severity of disease.

The high isolation rate in trachoma stage III indicates that there is continuing florid disease even in the presence of scarring. The progress from stage II to stage III can therefore not be regarded as improvement.

The authors are grateful to Dr Messadi and the staff of l'Institut d'Ophtalmologie, Tunisia, and to Dr C. R. Dawson, WHO Collaborating Centre for Reference and Research on Trachoma and other chlamydial Infections, Francis I. Proctor Foundation, University of California, San Francisco, USA, for their valuable assistance in arranging this programme and in the collection of the specimens.

We are indebted to the World Health Organisation and the Dulverton Trust for financia! support for part of this study.

\section{References}

Alani, M. D., Darougar, S., Burns, D. C. MacD., Thin, R. N., and Dunn, H. (1977). Isolation of Chlamydia trachomatis from the male urethra. British Journal of Venereal Diseases, 53, 88-92.

Darougar, S., and Jones, B. R. (1971). Conjunctival swabbing for the isolation of TRIC agent (Chlamydia). British Journal of Ophthalmology, 55, 585-590.

Darougar, S., Jones, B. R., Kinnison, J. R., VaughanJackson, J. D., and Dunlop, E. M. C. (1972). Chlamydial infection: Advances in the diagnostic isolation of Chlamydia including TRIC agent, from the eye, genital tract and rectum. British Journal of Venereal Diseases, 48, 416-420.

Darougar, S., Kinnison, J. R., and Jones, B. R. (1971). Simplified irradiated McCoy cell culture for isolation of Chlamydia. In Trachoma and related Disorders Caused by Chlamydial Agents, pp. 63-70. Edited by R. L. Nichols. Excerpta Medica, ICS 223.

Darougar, S., Treharne, J. D., Dwyer, R. St. C., Kinnison, J. R., and Jones, B. R. (1971). Isolation of TRIC agent (Chlamydia) in irradiated McCoy cell culture from endemic trachoma in field studies in Iran. Comparison with other laboratory tests for detection of Chlamydia. British Journal of Ophthalmology, 55, 591-599.

Darougar, S., Woodland, R. M., Forsey, T., Cubitt, S., Allami, J., and Jones, B. R. (1977). Isolation of Chlamydia from ocular infections. In Non-gonococcal Urethritis and related Infections, pp. 295-298. Edited by D. Hobson and K. K. Holmes. American Society of Microbiology.

Dawson, C. R., Daghfous, T., Messadi, M., Hoshiwara, I., and Schachter, J. (1976). Severe endemic trachoma in Tunisia. British Journal of Ophthalmology, 60, 245-252.

Dawson, C. R., Daghfous, T., Messadi, M., Hoshiwara, I., Vastine, D. W., Yoneda, C., and Schachter, J. (1974). Severe endemic trachoma in Tunisia. II. A controlled therapy trial of topically applied chlortetracycline and erythromycin. Archives of Ophthalmology, 92, 198-203.

Dawson, C. R., Jones, B. R., and Darougar, S. (1975). Blinding and non-blinding trachoma: assessment of intensity of upper tarsal inflammatory disease and disabling lesions. Bulletin of the World Health Organisation, 52, 279-282.

Gordon, F. B., Harper, I. A., Quan, A. L., Treharne, J. D., Dwyer, R. St. C., and Garland, J. A. (1969). Detection of Chlamydia (Bedsonia) in certain infections in man. I. Laboratory procedures: comparison of yolk sac and cell culture for detection and isolation. Journal of Infectious Diseases, 120, 451-462. 